\title{
Visitando as Missões Jesuíticas: um jogo para aprender com emoção ${ }^{1}$
}

\author{
Deise Juliana Francisco* \\ Glaucio José Couri Machado* \\ Rosemari Lorenz Martins \\ Daniela dos Santos Radtke ${ }^{* * * * * *}$ \\ Max Gunther Haetinger \\ Marcos Eduardo Casa \\ Tânia Rossetti ${ }^{* * * * * * * *}$ \\ Magda Bercht \\ Rosa Maria Vicari ${ }^{* * * * * * * * * * *}$
}

Resumo: Este artigo apresenta o jogo educacional "Visitando as Missões Jesuíticas", um jogo de escolha e decisão do tipo Role Play Game (RPG) Solo. Este foi criado para atender a demanda disciplina "Computação Afetiva", oferecida no segundo semestre de 2003, no Programa de Pós-Graduação em Informática na Educação/UFRGS. O objetivo do projeto foi o de criar um protótipo de um sistema educacional que inserisse aspectos emocionais na interação entre estudante e agente artificial, especialmente nos aspectos concernentes à personalidade e motivação. O jogo tem um forte valor histórico, especialmente no interior do estado do Rio Grande do Sul, palco de episódios da Guerra Guaranítica. Sendo assim, propõe-se a inserção em ambiente missioneiro, em que o(s) estudante(s) de quarta série poderá trabalhar com tempo histórico, características, fatos e o cotidiano em uma redução jesuíta do século XVIII. O projeto foi implementado como um conjunto de páginas web interativas e o padrão HTML, na composição de hipertextos, bem como a tecnologia Java para torná-las dinâmicos.

Palavras-chave: jogos, RPG, sistema educacional, computação afetiva e emoções

\section{A Visit to the Jesuit Missions: a game to learn with emotion}

Abstract: This paper presents an educational game entitled: "A Visit to the Jesuit Missions: a game to learn with emotion" in a solo Role-Play Game (RPG) of choice and decision. The objective is that of creating a prototype of an educational system that can take into account emotional aspects in the interaction between student and artificial agent, mainly concerning an improved system for the student. The game is inserted in a missionary environment where the grade school student can work with a history period, characteristics, facts and daily life in a Jesuit Mission during the 18th century. The system has a strong historical value, particularly within the Brazilian State of Rio Grande do Sul where the Guarani Indian War took place. The project was implemented as an interactive conjoint of Web pages with hypertext compositions as well as Java technology in order to make it dynamic.

Key words: game, RPG, educational system, affective computing and emotions

\footnotetext{
1 Este trabalho foi criado para atender a demanda disciplina "Computação Afetiva", oferecida no segundo semestre de 2003, no Programa de Pós-Graduação em Informática na Educação/UFRGS.

** Psicóloga, Mestre, URI - Campus Santo Ângelo, professora, dfrancis@ urisan.tche.br.

*** Cientista Social, Mestre, URI - Campus Santo Ângelo, professor, gcmachado@urisan.tche.br

**** Graduada em Letras, Mestre, FEEVALE, professora, rosel@ feevale.br

*****Graduada em Ciências da Computação, Mestre, PUC/RS, professora, daniradtke@ yahoo.com.br

******Graduado em Educação Física, Mestre, professor, maxcriar@terra.com.br

******** Graduado em Ciências da Computação Mestre, UCS, professor, mecasa@ ucs.br

********* Mestre, professora, taniammr@terra.com.br

********* Graduada em Ciências da Computação, Doutora, UFRGS, professora, bercht@ @inf.ufrgs.br

********** Graduada em Ciências da Computação, Doutora, UFRGS, professora, rosa@inf.ufrgs.br 


\section{Introdução}

Castells (2000) aponta que a sociedade contemporânea é caracterizada de forma ampla como a que gera informação e conhecimento e não mais produtos e riquezas. Tal processo se dá mediante a geração, armazenamento, recuperação, processamento e transmissão da informação que se retroalimenta e conecta culturas. Assim, a informação se transforma em conhecimento a partir da ação do sujeito sobre ela. Nesse contexto, a educação direciona suas ações para trabalhar com comunicação, interação, emoção e modos de aprender sintonizados com essa era histórica. Surge daí a idéia de construir um objeto de aprendizagem para aprender com emoção.

O projeto "Visitando as Missões: um jogo para aprender com emoção" é fruto do trabalho de um grupo de alunos da disciplina de "Computação Afetiva", oferecida no segundo semestre de 2003, no Programa de Pós-Graduação em Informática na Educação/UFRGS, que decidiu aplicar os conhecimentos trabalhados durante o semestre para construir um protótipo de jogo do tipo RPG Solo. Um grupo multidisciplinar foi formado por professores de diversas áreas, tais como Psicologia, Informática, Linguagens, Artes e Multimeios com o objetivo de integrar computação e emoção.

O foco de atenção do projeto nas Missões Jesuíticas deveu-se a seu valor histórico, especialmente no interior do Estado do RS, e à necessidade e importância de trabalhar o período histórico, os personagens, as crenças e o cotidiano das missões com crianças de quarta série. A quarta-série foi escolhida porque é nessa etapa em que as crianças normalmente estudam elementos do estado em que vivem, já estão plenamente alfabetizadas e já tem condições de leitura e escrita. Além disso, têm condições cognitivas de participar de jogos de escolha e decisão, tais como o RPG. Dessa forma, o jogo pode aliar-se às discussões em aula, tornando o estudo histórico mais vivo e participativo. O objetivo geral do projeto é projetar e construir um protótipo de jogo que leve em consideração a interação homem-computador, especialmente no tocante à personalidade e à motivação do usuário.

\section{Jogo e processo de aprendizagem}

Desde os primeiros anos de vida, os jogos e as brincadeiras são mediadores na relação das crianças com o mundo. $\mathrm{O}$ jogo possui aspectos fundamentais para a aprendizagem racional e o emocional, pois promove motivação, gerando maior participação e interação entre sujeito e conhecimento, proporcionando uma aprendizagem de qualidade e adaptada a cada sujeito e grupo. No jogo, as vivências acontecem de forma coletiva (aquilo que conquistamos na relação com os outros colegas) e individual (por causa dos diferentes papéis vividos em cada brincadeira). Piaget ilustra o caráter abrangente e imaginativo do jogo: [...] quando brinca a criança assimila o mundo à sua maneira, sem compromisso com a realidade, pois sua interação com o objeto não depende da natureza do objeto, mas da função que a criança lhe atribui. (Piaget, 1971).

Piaget aborda e valoriza, em suas fases de desenvolvimento da inteligência na criança, os tipos de jogos mais adequados para cada uma das fases, pois entende que o jogo é diferente para cada idade, cultura, meio e verdades de cada comunidade. Para Vygotsky (1997), a criança é introduzida no mundo adulto pelo jogo e sua imaginação, estimulada através dos jogos, pode contribuir para a expansão de suas habilidades conceituais.

Considerando-se estas teorias, quando um jogo é proposto, espera-se que as crianças sejam capazes de: 
1. respeitar limites - trabalhar a competição como parte e não como essência do jogo;

2. socializar - aprender a viver e conviver em sociedade, criando vínculos verdadeiros com os colegas, amplificando o sentido de grupo, gerando um ambiente de colaboração e cooperação, promovendo relações de confiança entre todos os aprendentes;

3. criar e explorar a criatividade - inovar e descobrir formas para se relacionar com a aprendizagem;

4. interagir - criar real interação entre o sujeito e o objeto de aprendizagem, de forma alegre e lúdica;

5. aprender a pesquisar (aprender a aprender) - desenvolver a busca, a iniciativa e tomada decisões.

O RPG é um tipo de jogo que vem se popularizando. A tradução mais aproximada seria "jogo de representação", surgiu no final da década de 70, nos EUA, como um desenvolvimento a partir dos Wargames, jogos, muitas vezes com miniatuaras, que simulavam situações de batalha, onde cada jogador controlava um exército. No RPG, cada jogador "interpreta" um personagem, um herói ou protagonista, e, conforme o jogo se desenvolve, as suas ações através do personagem irão ditar o andamento da história e os rumos que ela irá seguir. Para contar o início da história e situar os personagens de cada jogador, existe a função de mestre do jogo, a pessoa que irá também fazer a parte dos outros personagens com os quais personagens dos jogadores irão interagir seja pedindo informações, subornando, seduzindo, interrogando ou simplesmente entrando em combate. No RPG Solo há a participação de apenas um jogador.

\section{Emoção e ambientes de aprendizagem}

Piaget (1962) aborda a influência da afetividade nos processos de cognição e afirma que esta é importante em todo processo de formação e uso da inteligência do homem, afirmando que o afeto é uma condição necessária para a constituição da inteligência, porém insuficiente para explicar todo o processo de inteligência. $\mathrm{O}$ afeto é o motor da inteligência, pois se relaciona com interesse, necessidade, motivação que possibilitam colocar perguntas ou problemas que mobilizam o sujeito a pensar. Sendo assim, a afetividade pode levar à aceleração ou ao retardamento das estruturas cognitivas, porém não é a causa da formação das mesmas.

Os ambientes escolares e de aprendizagem, neste contexto, têm como uma de suas funções fomentar espaços e atividades que possam desenvolver também os aspectos afetivos sociais dos envolvidos e, dessa forma, favorecer os vínculos entre os sujeitos, além de favorecer os aspectos cognitivos. Nessa perspectiva, atividades lúdicas, psicomotoras, artísticas e em grupo podem ser aliados para favorecer a criação e manutenção de um ambiente em que os aspectos emocionais auxiliam.

Há um recurso que está sendo usado em modelagens para ambientes digitais de aprendizagem que levam em consideração os aspectos elencados acima: os agentes inteligentes a serviço da interação do usuário com os sistemas de ensino. Esses agentes são criados com o objetivo de ajudar o estudante ou o "navegador" a interagir com os espaços e seus conteúdos, em sistemas de FAQ, tutorias, chatterbot, ou mesmo como apoio à ação docente. Há os agentes modelados, que utilizam como interface entre sistema e usuários agentes "animados".

Os jogos de computadores utilizam-se deste cabedal de conhecimentos ao fazerem uso de agentes animados. Propõem, assim, uma relação lúdica e alegre entre máquina e usuário. Observa-se um movimento de transposição dos personagens lúdicos, 
normalmente modelados em duas dimensões (2D) para modelagens em três dimensões (3D), estes mais próximas da realidade das formas, ações e emoções humanas.

No âmbito pedagógico, a utilização de sistemas afetivos é importante, pois a emoção exerce um papel crítico na vida humana, incluindo aí a tomada de decisão, a percepção, a memória, a interação humana e a inteligência. Sendo assim, os sistemas podem atuar na comunicação empática, auxiliando a permanência do usuário no sistema, o recebimento de feedback e o auxílio na aprendizagem (Blocher, 1999). Têm sido utilizados controles de personalidade, motivação e de movimento corporal, a fim de possibilitar o acesso a emoções.

\section{Computação afetiva e emoções}

Computação afetiva é um campo da informática que leva em consideração as emoções ${ }^{i}$ tanto na confecção de hardwares quanto na de softwares. Para tanto, utiliza-se de conhecimentos de vários campos do conhecimento, tais como Informática, Educação, Psicologia, Sociologia, Inteligência Artificial, dentre outros. Para Bercht (2001), seu foco é o estudo e a compreensão do papel dos computadores na comunicação de emoções a agentes (artificiais ou biológicos), através de diferentes mídias.

Picard (s/d) afirma que, se máquinas tiverem habilidades emocionais, é possível construir robôs e objetos sintéticos capazes de emular a vida humana e animal, construir máquinas que são inteligentes, entender emoções a partir de sua modelização e, finalmente, construir máquinas que sejam menos frustrantes na interação homemcomputador. Além disso, os sistemas tornam-se mais acessíveis, possibilitando uma relação mais amigável do usuário com a máquina.

Dessa forma, os sistemas afetivos são construídos e têm capacidade de reconhecer, expressar, possuir ou desenvolver emoções. No contexto de implementar emoções, conforme Picard, pode-se apontar a existência de quatro elementos:

1.emotional appearance - inclui comportamento ou expressões que dão a impressão de que o sistema possui emoções (podem-se utilizar objetos sintéticos animados, feedback sonoro, facial e outras expressões comportamentais);

2. multiple levels of emotion generation - refere-se à geração de emoção;

3. emotional experience - refere-se à forma como são percebidos estados emocionais. Eles estão relacionados à consciência e esse é um problema para sistemas inteligentes;

4. a large category of Mind-body interactions Por último, o quarto diz respeito aos mecanismos de sinalização e de regulação das emoções que estão relacionadas às atividades cognitivas e corporais.

Há vários agentes na interação com sistemas, sendo eles humanos ou não. A definição de agente, porém, não é consensual na Inteligência Artificial. Usualmente é "associado a uma entidade que funciona contínua e autonomamente em um ambiente no qual existem outros processos e agentes" (Corrêa, 1994 citada por D'amico, 1999, p. 36). A um agente são atribuídas várias características, tais como: autonomia, mobilidade, comunicabilidade, discurso, inteligência, reatividade, habilidade social, representatividade, pró-atividade, flexibilidade, persistência, cooperatividade, comportamento adaptativo, confiabilidade, personalização, degradação gradual, aprendizagem, coerência, abstração e planejamento.

\section{Software: projeto e desenvolvimento}

O objeto de aprendizagem construído é um jogo tipo Role Play Game Solo. Tem como cenário São Miguel Arcanjo, uma das sete cidades das Missões, especificamente, 
a redução jesuítica. Nesse cenário, estão presentes três personagens, que fazem parte do jogo: o índio guarani, o padre jesuíta e o branco. O diagrama 1 mostra a estrutura do jogo:

Diagrama 1 - Apresentação do jogo

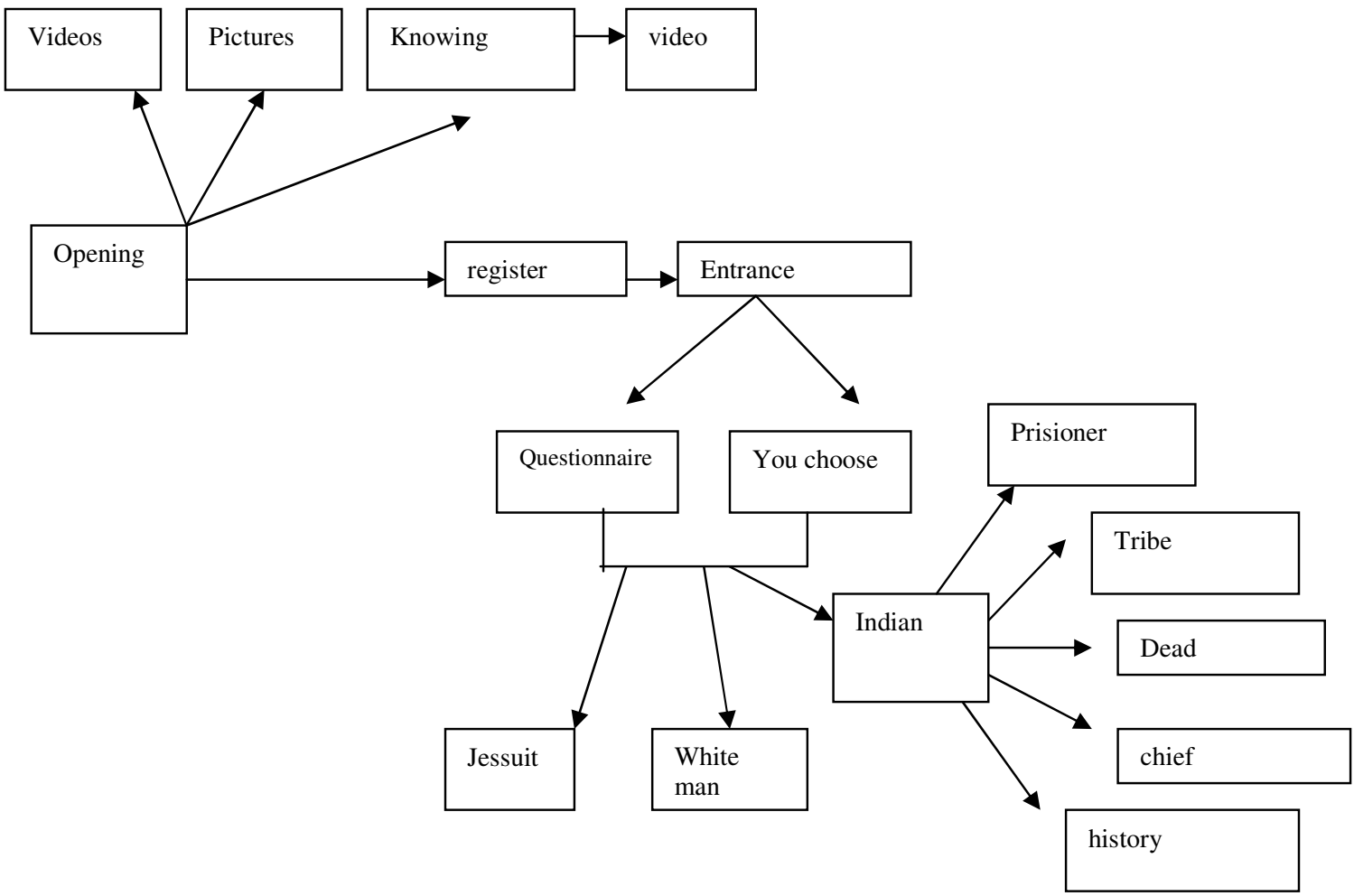

A tela de abertura apresenta várias possibilidades de entrada no jogo que podem ser telas de informação (vídeos, fotografias, projeto) e tela de registro ("entrando no jogo"), conforme visualizado na Figura 1.

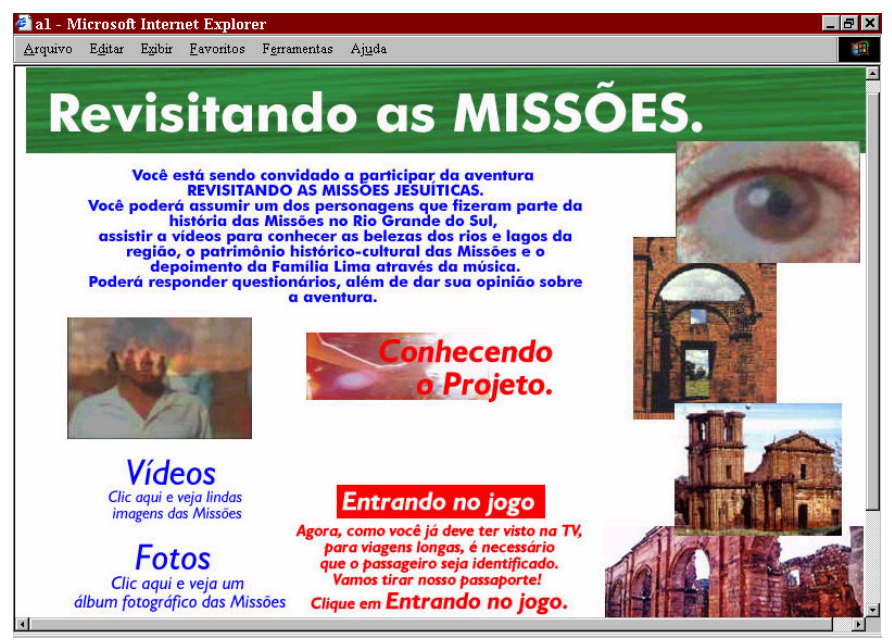

Figura 1 - Tela de abertura 
O registro do usuário é efetuado a partir do link "Entrando no jogo". Após o registro, o jogador escolhe o personagem (Figura 2). A escolha pode ser feita pelo próprio jogador ou por sugestão do sistema - questionário. Neste momento, o único personagem disponível é o índio guarani. Clicando no índio guarani é possível obter informações sobre a vida dos guaranis e sua rotina (tribo, cacique, mortos e prisioneiros) ou ir diretamente ao jogo (história).

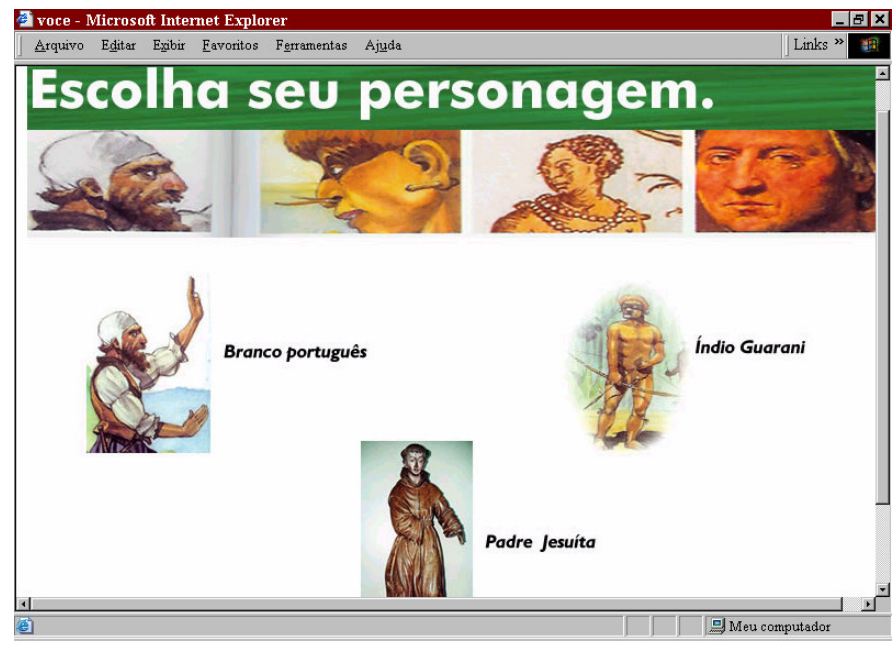

Figura 2 - Tela de escolha do personagem

É apresentado um questionário para definir o tipo de personalidade do jogador. O questionário é uma adaptação efetuada a partir das tabelas de tipos de personalidade baseada no MBTI, descrito em D'Amico (1999) e Pereira (1999). As perguntas foram adaptadas para o público infantil. O questionário compõe-se de 18 questões e, em cada uma delas, deve ser assinalada apenas uma alternativa.

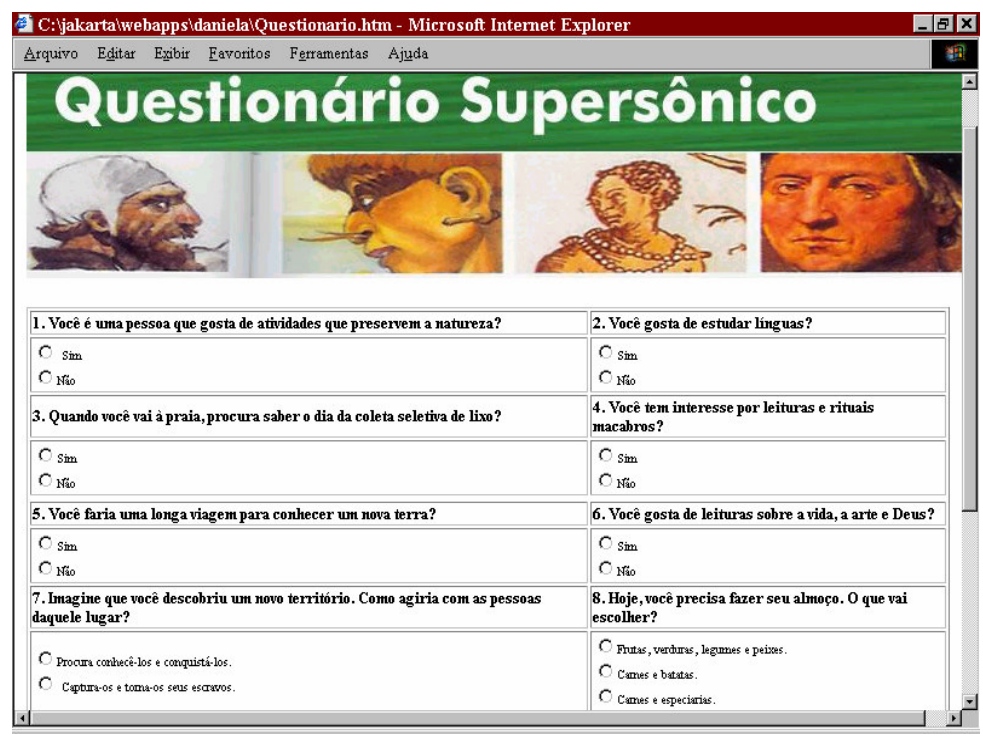

Figura 3 - Tela do questionário 
O escore do questionário determinará o tipo de usuário, conforme sua utilização do tempo. As informações colhidas com o questionário serão usadas para detectar e analisar aspectos da personalidade do jogador. Esses aspectos indicarão o período de tempo que cada estudante permanecerá em uma determinada página. Há três padrões de tempo no jogo: rápido, normal e lento.

Tabela 1 - Tempo

\begin{tabular}{|l|l|}
\hline Rápido & Extrovertido, intuitivo, filosófico-julgador, emotivo-sentimental \\
\hline Normal & Os outros \\
\hline Lento & Introvertido, sensitivo, perceptivo, racional-pensador \\
\hline
\end{tabular}

O tempo utilizado em cada página será acompanhado, observando-se a entrada e a saída das páginas. O período de tempo pode se localizar no intervalo padrão ou em diferentes faixas, maiores ou menores que o padrão. No protótipo inicial do jogo, mensagens e/ou vídeos de incentivo são apresentados para o jogador, quando necessário, para motivá-lo. Na transição entre páginas de um determinado caminho do jogo, o jogador deverá escolher entre três ícones, que representam "estados de espírito": triste/aborrecido, indiferente, alegre/feliz.

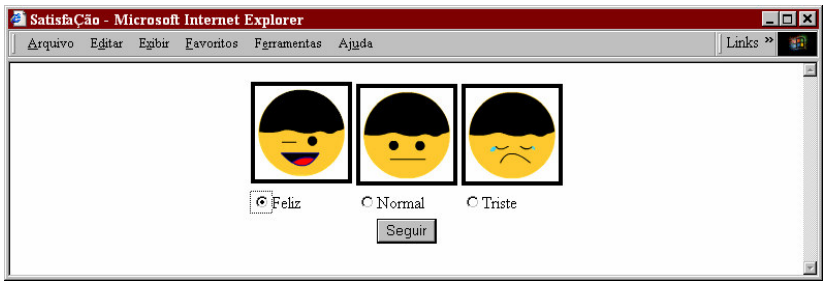

Figura 4 - Tela de estados de humor

Assim como o tempo, também os estados do humor determinarão a apresentação das páginas. A informação recebida durante a interação será armazenada em uma base de dados. Esta base será utilizada também para a troca de informação entre os programas que são operados em momentos diferentes do jogo. Os dados do questionário (definição do perfil) serão valiosos para organizar as respostas de acordo com cada decisão do jogador. Em cada tela, o jogador terá a possibilidade de expressar seu estado de motivação, de acordo com as faces que escolhe. Dependendo de suas respostas, serão emitidas mensagens de motivação para seguir no jogo. Dessa forma, os canais de afetividade tornam-se mais próximos, mantendo a confiança do usuário no jogo. O diagrama abaixo demonstra os trajetos possíveis. 
Diagrama 2 - Trajetos possíveis no jogo

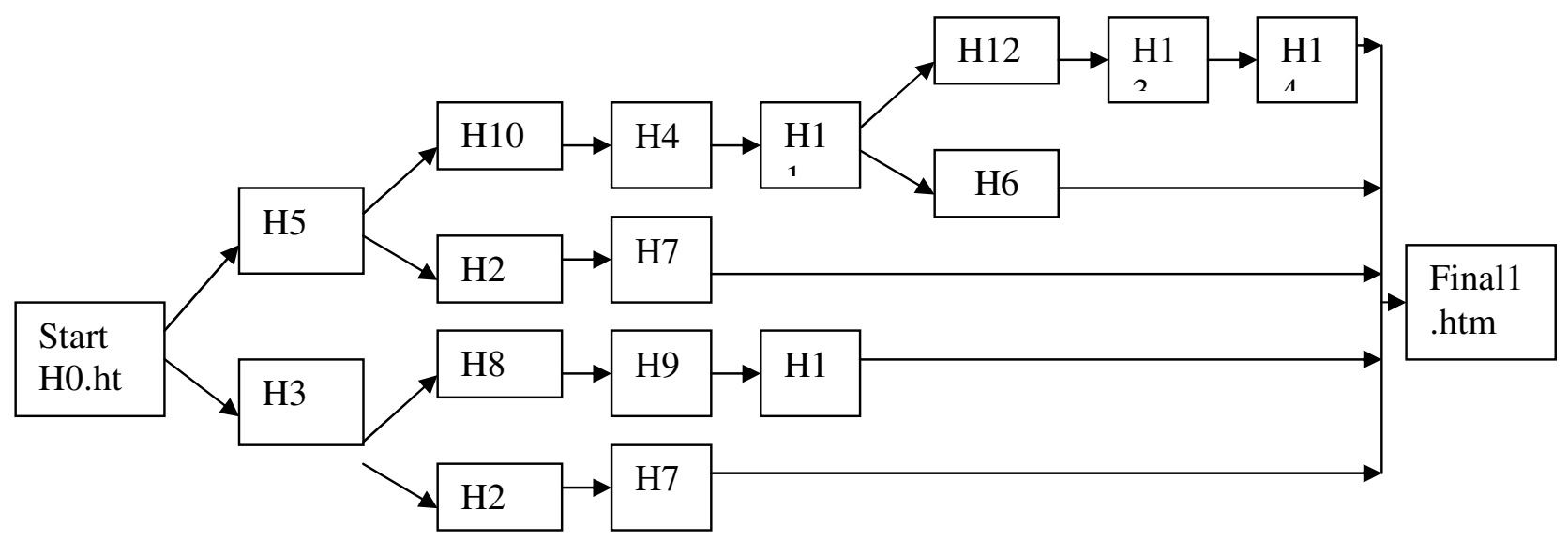

Entrando no jogo, a seqüência é constituída por opções que o jogador faz quando escolhe um determinado caminho.Em cada opção, caminhos são abertos. Por exemplo:

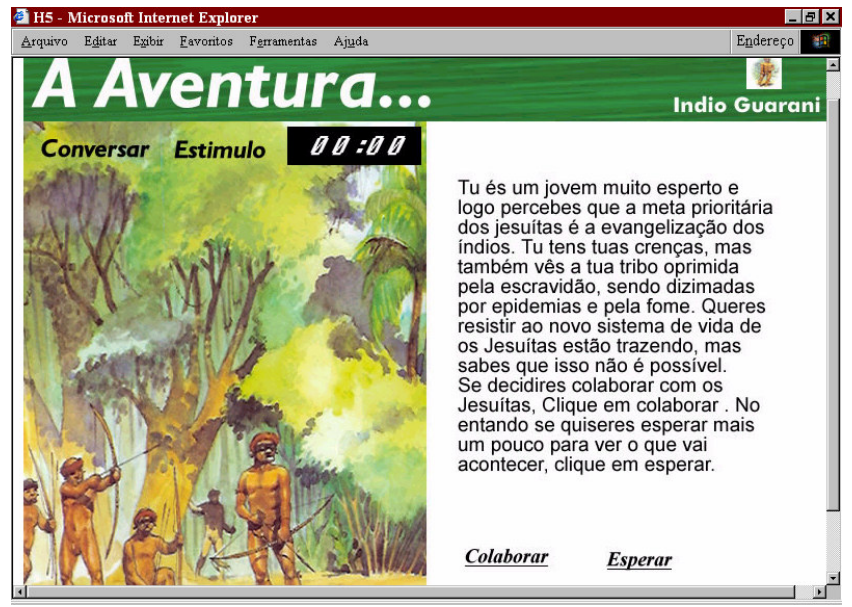

Figura 5 - Tela de opções do jogador

Os principais elementos tecnológicos envolvidos na implementação foram:

* HTML, Fireworks MX ferramentas para composição e produção visual das páginas, AceHTML, para efetuar pequenas alterações e incluir marcas mais específicas como, por exemplo, formulários HTML.

* Servlets - tecnologia Java

* Flash para preparar as faces que representam estados de humor. Esta tecnologia foi escolhida porque permite criar ícones animados, o que os torna mais interessantes e interativos. HTML.

* Applets - framework Java para a integração de programas Java a páginas

* Banco de dados relacional Access 
* Servidor Web Apache Tomcat - as páginas que compõem o jogo serão hospedadas em um servidor web Tomcat. O Tomcat é um servidor livre com capacidade para hospedar Servlets e páginas JSP.

\section{Conclusão}

Várias são as formas de romper paradigmas e mudar o layout da nossa tradicional sala de aula; no entanto, qualquer mudança representa um grande desafio. Certamente porque já que não se tem muitas certezas, mas muitas hipóteses, que justificam o desenvolvimento de determinados projetos, uma vez que já apresentam referencial teórico em outros contextos. Assim, acreditamos que uma metodologia que envolva o jogo, a interação, a emoção, a pesquisa, as novas tecnologias e a livre participação de todos resulte em maior eficiência e interesse pelo processo educativo, numa ampliação do contato dos alunos com novos conceitos, culturas, linguagens, mídias. Nessa perspectiva, desenvolvemos o projeto "Revisitando as Missões".

Por motivos diversos, o projeto ainda não está totalmente finalizado. Conseguimos implementar a história de apenas uma das personagens, o índio. No entanto, mesmo que tenhamos conseguido realizar apenas parte da proposta, já pudemos verificar que foi possível criar um objeto de aprendizagem que provavelmente motivará as crianças a aprender mais sobre as Missões Jesuíticas.

\footnotetext{
'Bercht (2001) diferencia emoção e afeto: “a) emoção é o nome de um conjunto de fenômenos derivados de um núcleo biológico comum aos seres vivos, como os primários (medo, alegria, tristeza, raiva, surpresa, repugnância), os secundários (ciúme, embaraço, culpa, orgulho,..), os de fundo (humor, calma, tensão), os impulsos e motivações [DAM2000]; e b) afetividade é a integração do domínio de emoções, dos sentimentos das emoções, das experiências sensíveis e da capacidade em se poder entrar em contato com sensações".
} 
Referências Bibliográficas:

BLOCHER, Katharine Howard. Affective Social Quest (ASQ) - Teaching Emotion Recognition with Interactive Media \& Wireless Expressive Toys. Master of Science in Media Technology Massachusetts Institute of Technology, June 1999.

BERCHT, Magda. Em direção a agentes pedagógicos com dimensões afetivas. Tese Doutorado. Porto Alegre : Programa de Pós-Graduação em Computação, UFRGS, 2001.

CASTELLS, Manuel.A sociedade em rede. A era da informação : economia, sociedade e cultura, v. 1. São Paulo: Paz e Terra, 2000

D’AMICO, Carmen Barbosa de. Aprendizagem estática e dinâmica em ambientes multiagentes de ensino-aprendizagem. Tese Doutorado. Porto Alegre : Programa de Pós-Graduação em Computação, UFRGS, 1999.

MBTI Disponível em <http://www.geocities.com/intpbr/mbti.html> Acesso em : $10 / 01 / 2004$.

PEREIRA, Adriana Soares. Um agente para seleção de estratégias de ensino em ambientes educacionais. Dissertação. Porto Alegre: Programa de Pós-Graduação em Computação, UFRGS, 1999.

PIAGET, Jean. A Epistemologia Genética. Petrópolis: Vozes, 1971.

PIAGET, Jean. The relation of affetivity to intelligence in the mental development of the child. [transl. by Pitsa Hartocollis]. In Bulletin of the Menninger clinic. - 1962, vol. 26, no 3. Three lectures presented as a series to the Menninger school of psychiatry March, 6, 13 and 22, 1961.

PICARD, Rosalind W. What does it mean for a computer to "have" emotions? Chapter to appear in: Emotions in Humans and Artifacts ed. by R. Trappl, P. Petta and S. Payr. Disponível em <http://www.media.mit.edu/ picard>, M.I.T Media Laboratory Technical Report \#534, Acesso em : 10/01/2004.

VYGOTSKY, L. A formação social da mente. SP, Martins Fontes, 1987. 